\title{
Macrophage activation syndrome (MAS) in juvenile systemic lupus erythematosus (JSLE): an underrecognized complication?
}

\author{
A Parodi*1, S Davì ${ }^{1}$, AB Pringe ${ }^{2}$, S Magni-Manzoni ${ }^{3}$, P Miettunen ${ }^{4}$, B Bader- \\ Meunier ${ }^{5}$, G Espada ${ }^{6}$, S Ozen ${ }^{7}$, D Wright ${ }^{8}, \mathrm{C} \mathrm{Magalhaes}^{9}, \mathrm{P} \mathrm{Woo}^{10}$, \\ R Kubchandani11, A Grom ${ }^{12}$, H Michels ${ }^{13}$, C Wouters ${ }^{14}$, CE Toro Gutierrez ${ }^{16}$, \\ G Sterba ${ }^{15}$, K Hayward ${ }^{17}$, D Guseinova18, A Fischer ${ }^{19}$, E Cortis ${ }^{20}$, \\ M Vivarelli20, A Pistorio' ${ }^{1}$, N Ruperto ${ }^{1}$, I Sala ${ }^{1}$, A Martini ${ }^{21}$ and A Ravelli21
}

\begin{abstract}
Address: ${ }^{1}$ IRCCS G. Gaslini, Genova, Italy, ${ }^{2}$ Hospital General de Ninos Pedro de Elizalde, Buenos Aires, Argentina, ${ }^{3}$ IRCCS Fondazione Policlinico S. Matteo, Pavia, Italy, ${ }^{4}$ Department of Pediatrics, University of Calgary, Calgary, AB, Canada, ${ }^{5}$ Hopital Necker Enfants Malades, Paris, France, ${ }^{6}$ Hospital de Ninos Ricardo Gutierrez, Buenos Aires, Argentina, ${ }^{7}$ Hacettepe University Children's Hospital, Ankara, Turkey, ${ }^{8}$ Children's Hospital Central California, Madera, CA, USA, ${ }^{9}$ Hospital das Clinicas, Faculdade de Medicina de Botucatu, Botucatu, Brazil, ${ }^{10}$ Great Ormond Street Hospital for Children, London, UK, ${ }^{11}$ Jaslok Hospital and Research Centre, Mumbay, India, ${ }^{12}$ Cincinnati Children's Hospital Medical Center, Cincinnati, OH, USA, ${ }^{13}$ Rheumatic Children's Hospital, Garmisch-Partenkirchen, Germany, ${ }^{14}$ Department of Pediatric Rheumatology, University Hospital of Leuven, Leuven, Belgium, ${ }^{15}$ Hospital de Clinicas Caracas, Caracas, Venezuela, ${ }^{16}$ Universidad Nacional de Colombia, Bogotà, Colombia,

${ }^{17}$ Children's Hospital, Seattle, WA, USA, ${ }^{18}$ Children's Clinical University Hospital, Riga, Latvia, ${ }^{19}$ Ospedale di Acireale, Acireale, Italy, ${ }^{20}$ Ospedale Pediatrico Bambino Gesù, Roma, Italy and ${ }^{21}$ IRCCS G. Gaslini and Università di Genova, Genova, Italy

* Corresponding author
\end{abstract}

from 15th Paediatric Rheumatology European Society (PreS) Congress

London, UK. 14-17 September 2008

Published: 15 September 2008

Pediatric Rheumatology 2008, 6(Suppl I):P236 doi:10.1 186/1546-0096-6-SI-P236

This abstract is available from: http://www.ped-rheum.com/content/6/SI/P236

(C) 2008 Parodi et al; licensee BioMed Central Ltd.

\section{Objective}

To define the characteristics of MAS complicating JSLE.

\section{Methods}

Patients with JSLE and MAS were collected from: 1) Gaslini Institute of Genoa, Italy; 2) PRINTO and PRCSG investigators; 3) literature. Control groups of JSLE without MAS included 33 patients with active lupus seen at Gaslini Institute (SLE-GI) and 387 patients from a multinational study of damage in JSLE (SLE-MS). Clinical and laboratory features of MAS with (BM+) or without (BM-) bone marrow demonstration of haemophagocytosis were contrasted each other and with those of lupus without MAS.

\section{Results}

$20 \mathrm{BM}+$ and $18 \mathrm{BM}$-patients with JSLE-associated MAS were identified. Comparison of percentage frequency of the main clinical and laboratory features of MAS in patient groups is shown in table 1 .

\section{Conclusion}

Features of MAS in patients with or without BM haemophagocytosis were comparable, except for a greater frequency of leukopenia in $\mathrm{BM}+$ patients. This suggests that this complication is more common than previously realized. All features but leukopenia and fever discriminated well between MAS and active lupus without MAS. 
Table I: Comparison of percentage frequency of the main clinical and laboratory features of MAS in partient groups. (NA: not available)

\begin{tabular}{lllll}
\hline & MAS BM+ & MAS BM- & SLE-GI & SLE-MS \\
\hline Fever & 95.0 & 83.3 & 21.2 & 64.2 \\
Hepatomegaly & 47.4 & 55.6 & 12.1 & 10.4 \\
CNS dysfunction & 37.5 & 28.6 & 3.0 & 8.5 \\
Haemorrhages & 40.0 & 33.3 & 9.1 & NA \\
Leukopenia & 90.0 & 44.4 & 63.6 & NA \\
Thrombocytopenia & 90.0 & 61.1 & 18.2 & NA \\
Hypertransaminasemia & 80.0 & 93.8 & 30.3 & NA \\
Hypertriglyceridemia & 75.0 & 88.2 & 20.0 & NA \\
Hypofibrinogenemia & 37.5 & 42.9 & 0 & NA \\
Hyperferiitinemia & 92.9 & 94.4 & 0 & NA \\
\hline
\end{tabular}

Publish with Bio Med Central and every scientist can read your work free of charge

"BioMed Central will be the most significant development for disseminating the results of biomedical research in our lifetime. " Sir Paul Nurse, Cancer Research UK Your research papers will be:

- available free of charge to the entire biomedical community

- peer reviewed and published immediately upon acceptance

- cited in PubMed and archived on PubMed Central

- yours - you keep the copyright 